\title{
A retrospective study on multiple renal arteries in Turkish population
}

\author{
Ragıba Zağyapan, Can Pelin, Ayla Kürkçüoğlu \\ Department of Anatomy, Faculty of Medicine, Başkent University, Ankara, Turkey
}

\begin{abstract}
Objectives: Since the urogenital system has a complicated embryological development the congenital anomalies and variations in these structures are common, and their incidence shows social, ethnic and racial difference. Especially the variations in the vascular structure of the kidneys gain importance because of the widespread development in transplantation surgery. This preliminary study is a retrospective archive study on multiple renal arteries, and represents the central Anatolian population. Our main purpose is to determine the incidence of multiple renal arteries in the central Anatolia region, and to evaluate their types.
\end{abstract}

Methods: Angiographic images of 150 individuals were examined for the study.

Results: The incidence of multiple renal arteries was observed as $42 \%$. This result was a little higher when compared with the other studies on Turkish population, but correlated with general literature.

Conclusion: These results indicate the need of a detailed radiological examination before the surgical approaches.

Key words: multiple renal arteries; variation; radiology

Anatomy 2009; 3: 35-39, C 2009 TSACA

\section{Introduction}

Since the embryological development of urogenital system is highly complicated the congenital anomalies or variations of these organs are relatively higher when compared with the others. Structural or localization anomalies of the kidneys or vascular variations are various. Some of them do not even cause clinical symptoms and require treatment. However some of them are predisposing to some pathological disorders because of the decrease in the blood supply or urinary flow. ${ }^{1}$

Most of the anomalies are the persistent structures those do not disappear during the embryological process or occur due to a delay at the end of the development. ${ }^{2}$ As the kidneys ascend from the pelvis during the embryological development they receive their blood supply from the vascular structures close to them. Initially renal arteries are the branches of common iliac arteries. Later, while the kidneys ascend they receive new branches from the aorta, and the inferior branches disappear. In the ninth week of the intrauterine life the kidneys come in to contact with the suprarenal glands and the ascent stops. The kidneys receive their most cranial branches from the aorta. These are the permanent renal arteries. The permanent mesonephric arteries other then renal arteries are the middle supra renal, gonadal, and inferior phrenic arteries. ${ }^{3}$ This continuously changing blood supply of the kidneys as they ascend explains the high incidence of the variations in the blood supply to the kidneys.

The frequency of multiple renal arteries ranges from $9 \%$ to $76 \%$, but generally changes between 28 and $30 \% .^{4-6}$ They are evaluated in two subgroups; early divi- 
sion of the segmental arteries before entering from the renal hilum, and extra renal arteries.

Most of the studies on renal artery variations in the Turkish population are case reports. ${ }^{7-9}$ Comprehensive studies on the incidence and types of renal artery anomalies are limited, especially for the central Anatolian population. ${ }^{10-11}$ The main purpose of this preliminary study is to determine the incidence of multiple renal arteries among the individual who would be operated as donors in the central Anatolia region, and to evaluate their types.

\section{Materials and Methods}

Angiographic images of 150 individuals aged between 36 -52 years (mean age $=41 \pm 2.44$ years) were examined for the study. Of these 150 individuals 79 were females and 71 were males. All the images were available from the archive of the radiology department of Başkent University Faculty of Medicine, and all the individuals were the ones examined as renal donors, and none of them had a known clinical disorder. Since angiography has been accepted as the gold standard for the assessment of renal vasculature in renal transplant donors, and as it is well known that this technique is the best one to determine the anatomical variations ${ }^{12}$ this study was planed as an examination on angiographic images.

\section{Results}

When the radiological images were evaluated, in 87 of 150 cases $(58 \%)$ a single renal artery was supplying a kidney. In the remaining 63 (42\%) individuals multiple renal arteries were observed. In 24 of these 63 cases (37\%) with variation, double renal arteries were seen on the right side and in 29 (45\%) on the left side (Figure 1). In $8(12 \%)$ individuals bilateral double renal arteries, and in 4 of them triple renal arteries on the right side were detected (Figure 2).

\section{Discussion}

Renal artery variations are common in the population and gained importance in the last decade because of the widespread development in transplantation surgery.
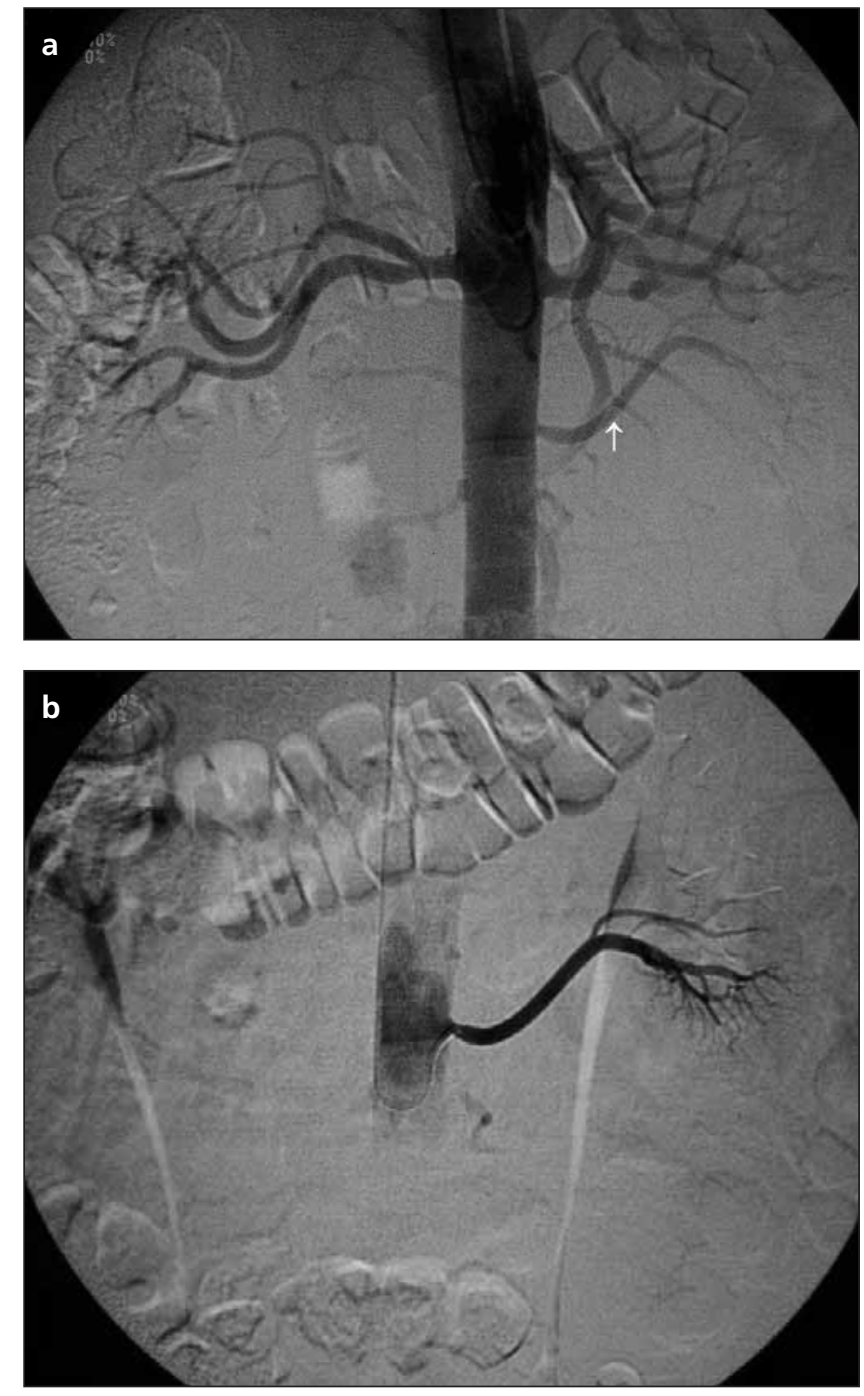

Figure 1. (a) In nonselective renal angiogram, early segmentation on the right side, and double renal arteries on the left. White arrow indicates the aberrant renal artery. (b) In a selective renal angiogram the aberrant renal artery supplying the inferior pole.

Variations in the renal vasculature are of importance not only for the surgeons, but for the radiologists, especially in the interventional radiological approaches.

Renal vasculature had been examined and studied by using several methods. Cadaver dissections are widely used to determine anatomical variations especially in earlier years. However the lack of cadavers even for anatomy education prevents the studies on the incidences of anatomical variations. Radiological examination is the best way to determine the vascular variations and to evaluate their incidences. Conventional angiogra- 

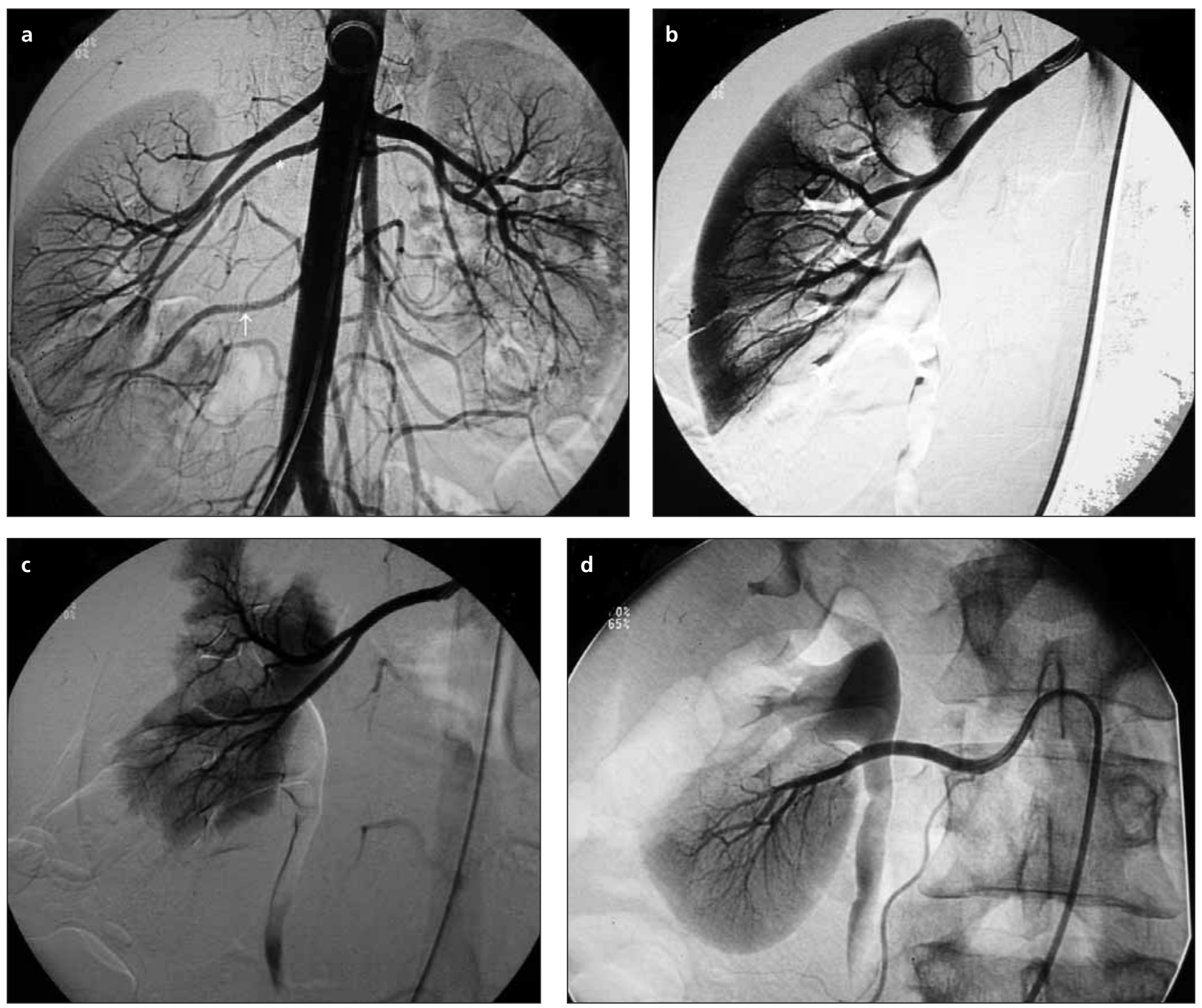

Figure 2. (a) Triple renal arteries on the right side (white arrow indicates the aberrant artery), and the renal segments supplied by them (b-d).

phy has been accepted as the gold standard for the assessment of renal vasculature in renal transplant donors. However in resent years it is being replaced by computed tomographic angiography and MR angiography since it is an invasive technique. ${ }^{12-14}$ However since we only focused on the existence and the types of the variations but not on the length and caliber of the vascular structures in the present study conventional angiographic images available from the department of radiology had been used.

According to the classical anatomy text books in $70 \%$ of the individuals a single renal artery is present, origi- nating from abdominal aorta, mainly at the level of L1 and L2 vertebrae. However they may vary in their level of origin and in their caliber, obliquity, and precise relations. ${ }^{15}$ Kadir (1991) reported in his study that in $75 \%$ of the individuals renal artery arise from abdominal aorta at the level of L1-L2 vertebrae. ${ }^{16}$ On the other hand Özkan et al. declared only $23 \%$ and $22 \%$ of renal arteries originated between L1-L2 intervertebral disc on the right and left sides respectively. ${ }^{4}$ However when they evaluated the renal arteries originating between T12-L2 vertebrae their statistical result were closer to the ones by Kadir. In another study on 30 cadavers by Sancak et al. 
(1980) renal arteries were reported arising from abdominal aorta $1.5 \mathrm{~cm}$ below the superior mesenteric artery. ${ }^{17}$ In the present study in $93 \%$ of the cases with no vascular anomaly renal arteries were arising from abdominal aorta at the level of T12-L2 vertebrae.

Accessory arteries, if they are present, arise from the abdominal aorta either above or below the renal artery and fallow it to the renal hilum. ${ }^{15}$ An accessory renal artery may also pass to the superior or inferior renal pole. The ones to the inferior pole of the kidney cross the ureter anteriorly and may cause hydronephrosis. Accessory vessels rarely arise from the celiac or superior mesenteric arteries or from the common iliac arteries. ${ }^{15}$ In the present study no accessory arteries were observed arising from superior or inferior mesenteric arteries or from common iliac arteries. Moar and Tobias reported the incidence of multiple renal arteries as $25-50 \%$ and also added that in most of the cases only one accessory renal artery had been observed, but in a few of them more than one, even five accessory arteries exist. In another study on 133 cases. ${ }^{18}$ Sampaio and Passoss evaluated 266 angiographic images and reported arterial variations in $30 \%$ of them. ${ }^{19}$ Novic et al. reported the incidence of multiple renal arteries as $23 \%$ and $10 \%$ for unilateral and bilateral cases respectively. ${ }^{20}$ In a study on Turkish population in $18-30 \%$ of potential donors for renal transplantation multiple renal arteries were observed. ${ }^{21}$ In another study representing Turkish population 90 fetuses were dissected after colored latex had been injected into the vessels. No variation had been observed in $75 \%$ of the cases, double hilar artery in $11.1 \%$, an inferior polar artery in $10.5 \%$, and a superior polar artery in $3.3 \%$ of the specimens had been determined. ${ }^{22}$ The incidence of multiple renal arteries in the present study was $42 \%$, higher when compared with the other studies in Turkish population. The probability of having bilateral multiple renal arteries change between $5-10 \%{ }^{4,20-23}$ In the present study the frequency of bilateral multiple renal arteries was $12 \%$. Sampaio and Passos reported no side difference related with the existence of multiple renal arteries. ${ }^{10}$ Though no side difference was observed for the double renal arteries also in the present study, all the triple renal arteries were on the right side.
However as they were only four, a reliable statistical evaluation was not possible.

On the other hand it is known that the frequency of renal artery variations shows social, ethnic, and racial differences. It is more common in Africans (37\%) and Caucasians $(35 \%)$ when compared with other populations, and less common in Hindus (17\%). ${ }^{4}$ An incidence as $42 \%$ for Turkish population is an unexpected result.

Variations in the renal vasculature is common in the population, and post surgical complications and the risk of kidney loss is higher in the cases with multiple renal arteries when compared with the kidneys having one renal artery. The results of the present study indicate the incidence of multiple renal arteries as $42 \%$ in the central Anatolia region, relatively higher as it has been reported in the literature, and emphasis the necessity of angiographic examination for evaluating renal vasculature before the transplantation surgery.

\section{References}

1. Campbell MF. Anomalies of kidney. In: Campbell MF, Harrison JS, eds. Urology. 3rd ed. Vol. 2. W.B. Saunders: Philadelphia; 1970. p. 1416-86.

2. Netter FH. Kidneys, ureters and urinary bladder. The Ciba Collection of Medical Illustrations. Vol. 6. 1973. pp. 17, 35, 230, 233.

3. Moore KL. The Developing Human. 4th ed. W.B. Saunders Philadelphia; 1988. p. 250-1.

4. Özkan U, Oğuzkurt L, Tercan F, Kızılkılıç O, Koç Z, Koca N. Renal artery origins and variations: angiographing evaluation of 855 consecutive patients. Diagn Interv Radiol 2006; 12: 183-6.

5. Khamanarong K, Prachaney $\mathrm{P}$, Utaravichien A, Tong-Un T, Sripaoraya K. Anatomy of renal arterial supply. Clin Anat 2004; 17 : 334-6.

6. Satyapal KS, Haffejee AA, Singh B, Ramsaroop L, Robbs JV, Kalideen IM. Additional renal arteries incidence and morphometry. Surg Radiol Anat 2001; 23: 33-8.

7. Bayramoğlu A, Demiryürek D, Erbil KM. Bilateral additional renal arteries and an additional right renal vein associated with unrotated kidneys. Saudi Med f 2003; 24: 535-7.

8. Tanyeli E, Üzel M, Soyluoğlu AI. Complex renal vascular variation: a case report. Ann Anat 2006; 188: 455-8.

9. Peştemalcı T, Mavi A, Yıldız YZ, Yıldırım M, Gümüşburun E. Bilateral triple renal arteries. Saudi $\mathcal{F}$ Kidney Dis Transpl 2009; 20: 468-70. 
10. Arıncı K, Elhan A. A. renalis'in sayı anomalileri ve bunların klinik önemi hakkında incelemeler. Ankara Üniversitesi Tip Fakiiltesi Mecmuası (Ankara) 1971; 24: 548-73.

11. Ulutaş İ, Yurtseven M, Aycan K. A. renalis'in çıkış ve sayı anomalilerinin araştırılması. Ege Üniversitesi Tip Fakiiltesi Dergisi (Izmir) 1987; 26: 11-7.

12. Bia MJ, Ramos EL, Danovitch GM, et al. Evaluation of living renal donors. The current practice of US transplant centers. Transplantation 1995; 60: 322-7.

13. Firat A, Akın O, Ağıldere AM, Aytekin C, Haberal M. Contrastenhanced resonance angiography: evaluation of renal arteries in living renal transplant donors. Eur 7 Radiol 2004; 52: 84-93.

14. Türkvatan A, Özdemir M, Cumhur T, Ölçer T. Multidetector CT angiography of renal vasculature: normal anatomy and variants. Eur Radiol 2009; 19: 236-44.

15. Glass J ed. Kidney and Ureter. In: Standring S, ed. Gray's Anatomy. 39th ed. Churchill Livingstone: London; 2005. p. 1274-6.

16. Kadir S. Kidneys. In: Kadir S, ed. Atlas of Normal and Variant Angiographic Anatomy. Philadelphia: W.B. Saunders Company; 1991. p. 387-429.
17. Sancak B, Deva E, Özkul E, Zağyapan R Multiple renal arterler. Hacettepe Tip Cerrabi Bülteni (Ankara) 1980; 13: 283-9.

18. Moar JJ, Tobias PV. Multiple renal arteries. S Afr Med 71985 ;67: 399.

19. Sampaio FJ, Passos MA. Renal arteries: anatomic study for surgical and radiological practice. Surg Radiol Anat 1992; 14: 113-7.

20. Novic AC, Magnusson M, Braun WE. Multiple artery renal transplantation; emphasis on extracorporeal methods of donor arterial reconstruction. F Urol 1979; 122: 731-5.

21. Ersöz S, Tüzüner A, Erkek B, Esen S, Anadol E. Double renal arteries in living-related kidney transplantation. Transplant Proc 2000; 32: 604 .

22. Çiçekçibaşı AE, Ziylan T, Salbacak A, Şeker M, Büyükmumcu M, Tuncer I. An investigation of the origin, location and variations of the renal arteries in human fetuses and their clinical relevance. Ann Anat 2005; 187:421-7.

23. Emiroğlu R, Köseoğlu F, Karakayalı H, Bilgin N, Haberal M. Multiple-artery anastomosis in kidney transplantation. Transplant Proc 2000; 32: 617-9.

Correspondence to: Ayla Kürkçüoğlu, MD, PhD Department of Anatomy, Faculty of Medicine, Başkent University, Bağlıca Campus Etimesgut, Ankara, Turkey Phone: +903122341010/1524 e-mail: kayla@baskent.edu.tr Conflict of interest statement: No conflicts declared. 